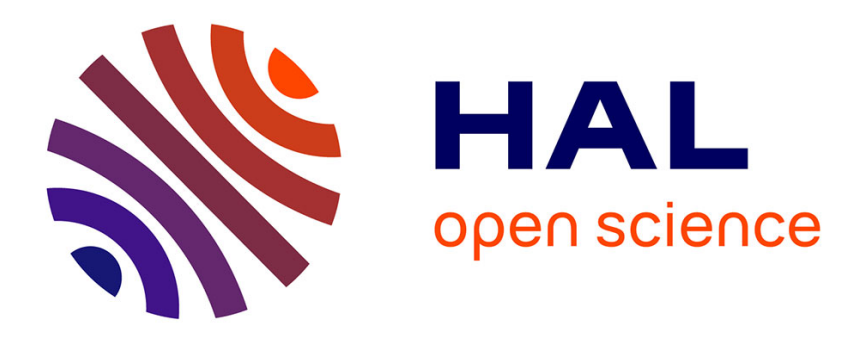

\title{
Thermomechanical Properties of Polycrystalline Vanadium in Compression
}

\author{
A. Lennon, K. Ramesh
}

\section{To cite this version:}

A. Lennon, K. Ramesh. Thermomechanical Properties of Polycrystalline Vanadium in Compression. Journal de Physique IV Proceedings, 1997, 07 (C3), pp.C3-559-C3-564. 10.1051/jp4:1997396 . jpa00255553

\section{HAL Id: jpa-00255553 https://hal.science/jpa-00255553}

Submitted on 1 Jan 1997

HAL is a multi-disciplinary open access archive for the deposit and dissemination of scientific research documents, whether they are published or not. The documents may come from teaching and research institutions in France or abroad, or from public or private research centers.
L'archive ouverte pluridisciplinaire $\mathbf{H A L}$, est destinée au dépôt et à la diffusion de documents scientifiques de niveau recherche, publiés ou non, émanant des établissements d'enseignement et de recherche français ou étrangers, des laboratoires publics ou privés. 


\title{
Thermomechanical Properties of Polycrystalline Vanadium in Compression
}

\author{
A.M. Lennon and K.T. Ramesh \\ Laboratory for Impact Dynamics and Rheology, Department of Mechanical Engineering, Johns Hopkins \\ University, Baltimore 21015, U.S.A.
}

\begin{abstract}
The mechanical behavior of commercially pure polycrystalline vanadium $(99.8 \%)$ has been characterized in compression over a strain rate range of $10^{-4}$ to $6 \times 10^{3} \mathrm{~s}^{-1}$. In addition, the temperature dependence of the flow stress of vanadium has been examined over a range of temperatures from 25 to $700^{\circ} \mathrm{C}$ for a strain rate of $10^{-3} \mathrm{~s}^{-1}$. Optical metallography of the deformed specimens revealed no twins, deformation bands or microcracks, suggesting that the deformation proceeded largely by crystallographic slip. The strain rate and temperature dependence of the strain hardening rate and flow stress is indicative of a BCC material, although a pronounced local peak in the flow stress was observed at about $400^{\circ} \mathrm{C}$.
\end{abstract}

Résumé. Le comportement mécanique de polycristaux de Vanadium (pureté commerciale : $99,8 \%$ ) a été caractérisé en compression pour des taux de déformation allant de $10^{-4} \AA 6.10^{3} \mathrm{~s}^{-1}$. L'évolution de la limite d'élasticité en fonction de la température a par ailleurs été analysée sur une plage de 25 a $700^{\circ} \mathrm{C}$. L'observation en microscopie optique des échantillons déformés a montré l'absence de mâcle, de bande de déformation ou de micro-fissure, ce qui suggère un mode de déformation par glissement cristallographique. A l'exception d'une anomalie de limite élastique vers $400^{\circ} \mathrm{C}$, le taux de déformation et l'évolution de la limite d'élasticité en fonction de la température est caractéristique des métaux cubiques centrés.

\section{INTRODUCTION AND BACKGROUND}

The primary applications of vanadium have been in the nuclear power industry due to its high strength at high temperatures, low long term induced radioactivity levels, and corrosion resistance to liquid alkali metals [1]. In addition, vanadium has the highest strength to weight ratio of the refractory metals and is superconductive at liquid helium temperatures [2]. In this work, vanadium is a BCC material examined as part of a broader study of shear localization that compares the characteristics of BCC and HCP lattice structures. Vanadium is interesting because nearly all of its thermo-physical properties are very similar to those of HCP titanium which is known to exhibit shear localization at large strains in the pure form [3], and at smaller strains under certain alloying conditions [4].

The ductility of vanadium over a vast range of temperatures and strain rates has been investigated by many researchers $[5 ; 6,7,2]$, although some earlier research suggested brittle behavior at low temperatures, possibly due to higher impurity contents. Wang and Bainbridge [5] conducted low rate tensile experiments on high purity polycrystalline vanadium and concluded that the Peierls mechanism was dominant below about $200 \mathrm{~K}$ while dislocation-interstitial interactions were dominant at high temperatures. The important role of interstitial impurities in vanadium (a characteristic of $\mathrm{BCC}$ 
materials) has been documented by Vorob'eva and Gulyaev [8], Kainuma et al [9] and others $[6,10,11]$.

An increase in the strength of vanadium in a narrow temperature band around $500^{\circ} \mathrm{C}$ has been observed $[12,6]$, and is also thought to be the result of increased dislocation-interstitial interaction. Yoshinaga et al [6] relate the Portevin-Le Chatelier effect in vanadium (serrated yielding at elevated temperatures) to this local increase in strength. Serrations of various degrees on the stress/strain curves of vanadium have been observed, ranging from no serrations to large serrations related to twinning depending on the strain rate and temperature conditions $[6,13]$. Twinning has also been reported for very low temperatures [2] and very high strain rates [7]. Little previous work has been done to characterize the strain rate dependence of vanadium. Characterization of the deformation microstructures by TEM has been fairly limited [14, 13], but confirm that edge dislocations have a higher mobility (especially at high strain rates) than screw dislocations, which is characteristic of the BCC lattice. In addition, it has been shown that impurities can stabilize stacking faults within vanadium and other $\mathrm{BCC}$ structures [15].

\section{MATERIAL PREPARATION}

Commercially pure vanadium $(99.8 \%)$ in the form of an annealed 1" diameter rod was obtained from Teledyne Wah Chang. The impurity analysis taken from the surface of the lot is shown in Table 1. However, since specimens were cut from the interior of the rod, it is probable that the specimen material was of slightly higher purity. Figure 1 shows the initial microstructure. This section was made perpendicular to the rod's extrusion axis, but parallel sections revealed an identical structure. The average grain size was measured to be $11 \mu \mathrm{m}$, but

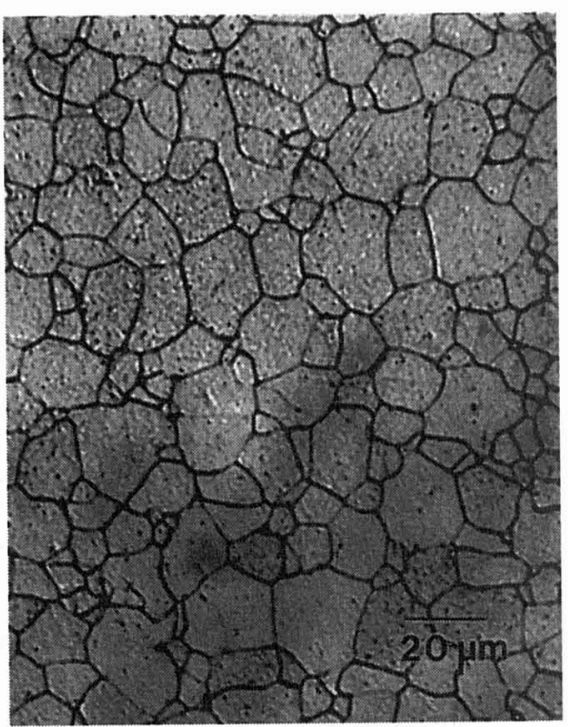

Figure 1: Undeformed vanadium grain structure there is clearly a somewhat bimodal distribution of grain sizes ranging from 5 to $25 \mu \mathrm{m}$.

Cylindrical quasistatic and dynamic specimens were cored from the interior of the rod using a wire EDM. Quasistatic specimens had a length to diameter ratio of 1.8 which is an ASTM standard for testing high strength materials at large strains. Specimens for high-rate testing had an L/D of 0.70 . Specimen axes were cut parallel to the axis of the original vanadium rod. 


\section{EXPERIMENTAL TECHNIQUES}

All quasistatic experiments were run on a servohydraulic MTS load frame in displacement control. With the ends of the specimens properly lubricated to allow homogeneous deformations throughout the length of the specimen, strain was determined from the crosshead displacement (measured with an LVDT). For room temperature experiments a high viscosity grease was used as a lubricant, while at high temperatures molybdenum disulfide powder was used. Transducer signals for load and displacement were captured using a high speed data acquisition board utilizing LabVIEW virtual instrument software.

High temperature experiments were conducted by enclosing the specimen and grid ends in a high temperature optical furnace. Although the furnace is capable of heating rates of well over $1000{ }^{\circ} \mathrm{C}$ per minute, the specimen must be held at temperature for about 15 minutes in order for the temperature of the grips (which are water cooled) to equilibrate. Otherwise, thermal expansion of the grips would contribute to the deformation of the specimen during the displacement controlled experiment. Argon gas is continuously blown across the specimen to slow the rate of oxidation.

A compression Kolsky bar was used for the high strain rate experiments. Only a brief description will be provided here, but interested readers are referred to references by Kolsky [16] and Coates and Ramesh [17]. The apparatus consists of two long metal bars that are designed to remain elastic throughout the experiment. These bars sandwich a small cylindrical specimen. A projectile impacts the end of the input bar which propagates an elastic compression wave toward the specimen. The component of the incident wave which is transmitted into the output bar contains information on the stress level within the specimen as a function of time. Similarly, the reflected portion of the incident wave contains information on the strain rate as a function of time, which can be integrated to yield strain. Strain gage signals are captured using a digital oscilloscope with twelve bit vertical resolution. Signals are then corrected to adjust for wave dispersion within the bars, and dynamic stress/strain curves are generated.

All Kolsky bar experiments were run in a recovery mode; that is, the specimen is recovered after being subjected to only one loading pulse. This is a simple matter of making the output bar shorter than the input bar so that the tensile unloading wave separates the output bar from the specimen before the reflection from the end of the input bar (which is compressive) arrives to reload the specimen. 


\section{RESULTS}

The vanadium tested was ductile for the entire range of strains, strain rates and temperatures examined. An impact test at a nominal strain rate of over $10^{4} \mathrm{~s}^{-1}$ and $100 \%$ true strain showed no microcracking or brittle nature. Figure 2 displays stress/strain curves for polycrystalline vanadium at room temperature $\left(25^{\circ} \mathrm{C}\right)$ over a range of strain rates from $10^{-4} \mathrm{~s}^{-1}$ to $6 \times 10^{3} \mathrm{~s}^{-1}$. Although the shape of the stress strain curves changes somewhat at small strains, the large strain behavior is indicative of the $\mathrm{BCC}$ lattice. It should be noted that neither experimental procedure used accurately reflects the small strain behavior. The quasistatic L/D ratio of 1.8 is too small to accurately measure elastic behavior. In the case of the Kolsky bar experiments, early strain information is inaccurate because it takes a short period of time to achieve a homogeneous stress state within the specimen. Figure 3 plots the flow stress at a fixed strain $(10 \%)$ as a function of strain rate. Because the strain hardening at large strains (over about 5\%) is independent of rate, the choice of the strain in plotting the rate sensitivity curve is not critical. Figure 3 shows that vanadium is strongly rate sensitive over this range of rates.

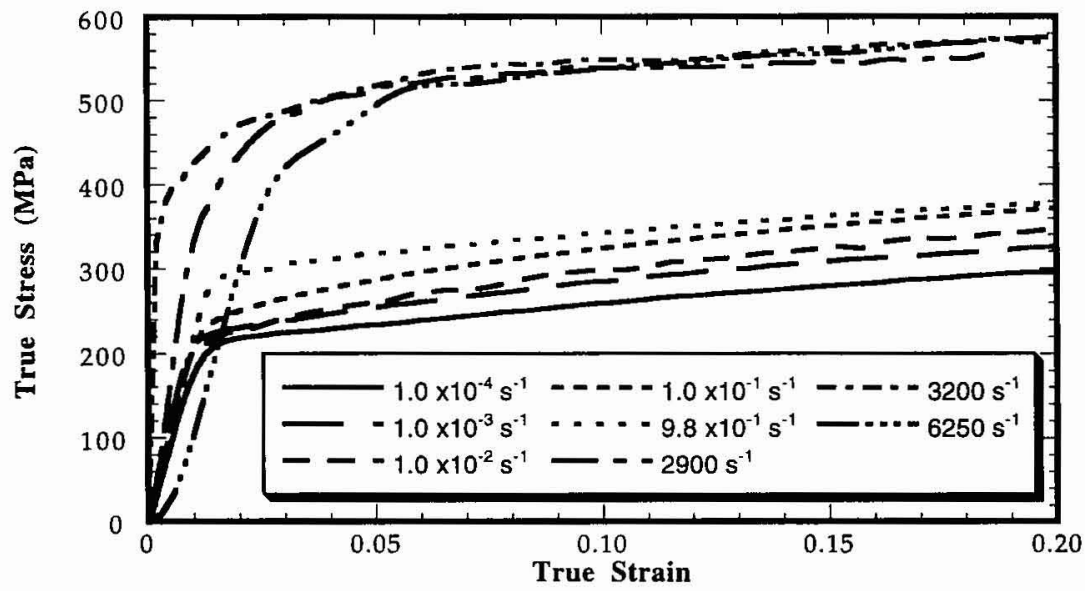

Figure 2: Stress/strain curves for vanadium at $25^{\circ} \mathrm{C}$

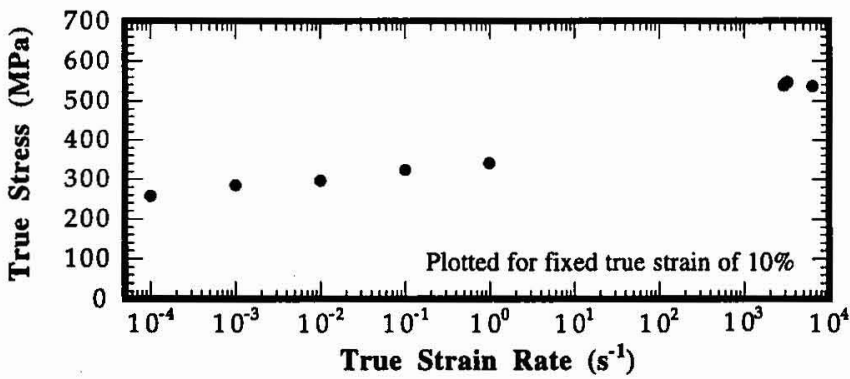

Figure 3: Rate sensitivity of vanadium at $25^{\circ} \mathrm{C}$ 
Figure 4 displays stress/strain curves for temperatures ranging from $25{ }^{\circ} \mathrm{C}$ to $500^{\circ} \mathrm{C}$. The temperature dependence appears similar to the rate dependence in that the strain hardening is unaffected, but the flow stress is not monotonically decreasing with temperature. Figure 5 plots the flow stress at $10 \%$ true strain as a function of temperature. There is a local maximum at about $400{ }^{\circ} \mathrm{C}$ which represents a stress level higher than the room temperature strength. It must be stated that the curve shown in Figure 4 merely illustrates the trend of the flow stress; further testing is required to adequately determine the material behavior.

\section{DISCUSSION AND CONCLUSION}

Optical metallography of the deformed specimens revealed no twins, deformation bands or microcracks, which suggests that the deformation was accomplished exclusively by crystallographic slip mechanisms for the entire range of strains, strain rates and temperatures. At this time it is unclear why no twinning was observed when Wang and

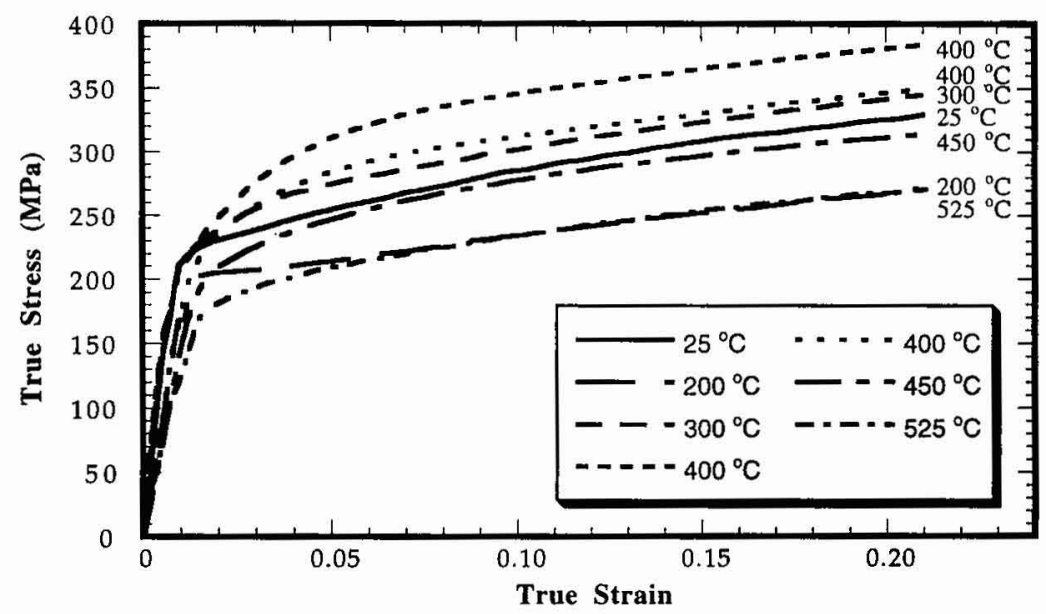

Figure 4: Stress/strain curves for vanadium at $10^{-3} \mathrm{~s}^{-1}$

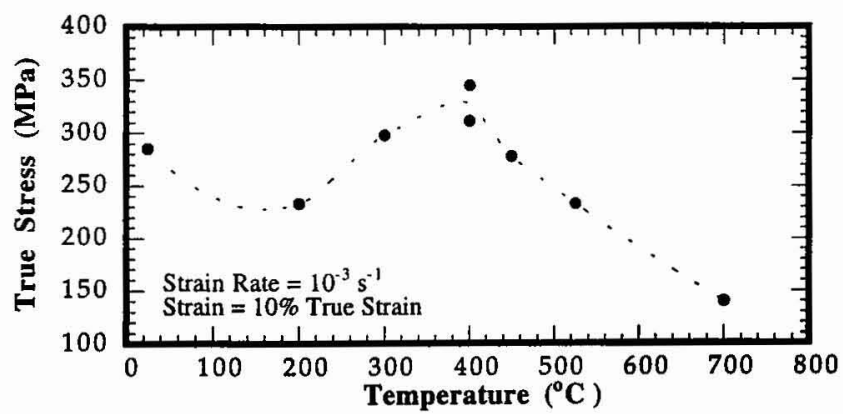

Figure 5: Temperature dependence of flow stress for vanadium 
Bainbridge [5], Yoshinaga et al. [6] and others have reported twins occurring under similar conditions. One possible explanation arises from the fact that the majority of such characterizations on vanadium have been done for quasistatic tension, not compression, and the twinning modes may well be different in compression. Another possible explanation is that the relatively small grain size allows for larger densities of mobile dislocations, suppressing the activation of twinning systems. A fairly high frequency scatter in the load transducer signals (scatter which increased with decreasing strain rate) may have been indicative of a modest Portevin-Le Chatelier effect, which can occur without twinning as described by Yoshinaga et al. [6] due to the pileup and sudden release of interstitial-laden dislocations.

The local increase in flow stress as a function of temperature near $400^{\circ} \mathrm{C}$ is most likely due to pinning of the existing dislocations by interstitial impurities $[6,13]$. Figure 4 shows that there was a considerable amount of variability in the measured stress value at $400^{\circ} \mathrm{C}$. Precision of the temperature control and repeatability of room temperature tests at the same strain rate suggested that some other factor was contributing to this variability. As mentioned in the section on experimental techniques, specimens are held at temperature (in this case $400{ }^{\circ} \mathrm{C}$ ) for approximately 15 minutes before undergoing deformation. This allows a considerable amount of time for the interstitial atoms to pin dislocations, and there may be some time dependence on the degree of dislocation pinning. Future experiments will quantify the effect of aging time on flow stress for high temperature deformations. This continuing study will also analyze the combined effects of temperature and strain rate as well as characterizing the dislocation structure operative for various strain rate and temperature regimes.

\section{References}

[1] R.E. Gold and R. Bajaj, J. Nuc. Mat. 122-123 (1984) p.759-766

[2] V.V. Abraimov, Yu.V. Yefimov, N.D. Kozlova, Ye.M. Savitskiy and V.I. Startsev, Phys. Met. Metallogr. 38 (1974) p.147-152

[3] D.R. Chichili, K.J. Hemker and K.T. Ramesh, in preparation

[4] M.G. da Silva and K.T. Ramesh, Mat. Sci. Eng. A, in press

[5] C.T. Wang and D.W. Bainbridge, Met. Trans. 3 (1972) p.3161-3165

[6] H. Yoshinaga, K. Toma, K. Abe and S. Morozumi, Phil. Mag. 23 (1971) p.1387-1403

[7] L.C. Chhabildas and C.R. Hills, Metallurgical Applications of Shock-Wave and HighStrain-Rate Phenomena, editors L.E. Murr, K.P. Staudhammer and M.A. Meyers (1986)

[8] L.P. Vorob'eva, A.P. Gulyaev and I.P. Druzhinia, Metal Sci. Heat Treat. 1-2 (1970) p.53

[9] T. Kainuma, N. Iwao, T. Suzuki and R. Watanabe, J. Nuc. Mat. 80 (1979) p.339-347

[10] J. Bressers and R. Creten, Scr. Metall. 11 (1977) p.33-36

[11] O.N. Carlson, D.K. Rehbein and K.E. Bogacik, Strength of Metals and Alloys, v.2 Fifth International Conference, Aachen, W. Germany (1979) p.995-1000

[12] G.A. Henshall and S.G. Torres, Lawrence Livermore National Laboratory Report UCRL114591 , Dec. 1993

[13] Ye.P. Kostyukova and I.V. Kostina, Phys. Met. Metall. 61 n.5 (1986) p.166-169

[14] F. Louchet and L.P. Kubin, Scr. Metall. 9 (1975) p.911-916

[15] T.C. Lindley and R.E. Smallman, Acta Metall. 11 (1963) p.361-371

[16] H. Kolsky, Proc. Phys. Soc. 62B (1949) p.676

[17] R.S. Coates and K.T. Ramesh, Mat. Sci. Eng. 145 (1991) p.159-166 